\title{
Sistema Pré-Fabricado em Pré-Moldado de Concreto para Instalações Provisórias de Canteiros de Obra
}

\author{
Nery Knöner \\ Fernando Menezes de Almeida Filho \\ Marcelo de Araújo Ferreira
}

\section{Introdução}

No Brasil, nas últimas décadas, houve um aumento significativo no uso de estruturas pré-fabricadas em concreto em virtude do desenvolvimento dos componentes e da facilidade de utilização desse sistema para obras comerciais, residenciais e esportivas, agregando vantagens, como rapidez e facilidade de execução, redução de desperdícios e segurança na montagem.

O sistema em pré-moldados de concreto proporciona uma construção limpa, racional e com menos desperdício de materiais, além de possibilitar maior conforto e bem-estar aos seus ocupantes. Como estratégia de concepção, procura utilizar componentes e processos padronizados, bem como aproveitar mais eficientemente os recursos disponíveis. Para Van Acker (2002), com os pré-moldados de concreto é possível atender os requisitos de industrialização, mesmo sem a produção em escala, obtendo um processo de produção eficiente, combinado com o trabalho especializado e a padronização de soluções construtivas. 
Segundo Serra et al. (2005), a industrialização da construção civil, por meio da utilização de peças de concreto pré-fabricados, promoveu, no Brasil e no mundo, um salto de segurança e organização nos canteiros de obras, devido ao uso de componentes industrializados com alto controle de produção, com materiais de qualidade, fornecedores selecionados e mão de obra qualificada.

A construção em elementos pré-fabricados em concreto não se limita apenas a fabricar peças fora do canteiro, mas engloba todo um sistema construtivo com características próprias, que devem ser preconizadas desde o início do projeto do empreendimento (FIB, 2012). Visto que o concreto possui boa inércia térmica e resistência ao fogo, os componentes gerados, como as paredes, podem ser projetados para atender determinadas especificidades, como reduzir os ruídos, devido à sua densidade.

Para Knöner (2014), o uso dos pré-moldados possui potencial de aplicação para instalações provisórias em canteiros de obra, considerando inclusive a necessidade da desmontagem e reutilização dos componentes em diferentes obras, além das outras vantagens levantadas. Para esse autor, a desmontagem com fins de remontagem é uma característica não comumente citada, mas deve ser considerada desde o início do processo de projeto.

Existem poucos fabricantes que fornecem opções de instalações provisórias em concreto pré-moldado no mercado brasileiro. Um deles é a empresa Prefacc (PREFACC, 1992) sediada em Uberlândia, Minas Gerais. Segundo o referido fabricante, trata-se de um sistema construtivo formado por placas de concreto celular autoclavado, com módulos de 0,60 m de largura, interligados por perfilados metálicos, que podem chegar até $3 \mathrm{~m}$ de altura. Entre os clientes da Prefacc, podem ser verificadas empresas de grande porte, consórcios e órgãos públicos.

Além deste tipo de instalações provisórias, são oferecidas pelo mercado diferentes soluções construtivas, como o uso de madeira ou de chapas metálicas (DIAS; SERRA, 2013), mas faltam dados para determinar o atendimento às condições de desempenho de cada solução.

Apesar da existência das soluções comerciais, no Brasil, a maioria das instalações provisórias dos canteiros de obras ainda é precária e não projetada com vistas ao seu melhor funcionamento. Considerada como uma instalação temporária, não se costuma seguir regras de projeto e de segurança, e somente em alguns casos, a NR18 - Condições e meio ambiente de trabalho na indústria da construção (BRASIL, 2015), que preconiza condições mínimas de uso e segurança, é atendida.

Também não são comumente considerados os requisitos de uso e operação desses tipos de instalações, como resistência estrutural, desempenho térmico, estanqueidade à agua, entre outros, os quais são prescritos pelas normas técnicas.

Dessa forma, este capítulo visa apresentar uma proposta de instalação provisória em pré-moldado de concreto para uso em canteiro de obra e, em seguida, 
analisar os principais requisitos técnicos identificados para a concepção de um sistema construtivo. A proposta surge também no contexto de encontrar um sistema eficiente, de construção rápida, econômico, com redução significativa na produção de resíduos e que proporcione qualidade do ambiente de trabalho.

O sistema construtivo desenvolvido possibilita atender a demanda de mercado para construção de canteiros de obra de acordo com os quesitos da NR-18 - Condições e meio ambiente de trabalho na indústria da construção (BRASIL, 2015) e NBR 12.284 (ABNT, 1991). O sistema pré-fabricado atende aos requisitos de rapidez na montagem, eliminação de resíduo e baixo custo, além de utilizar um processo construtivo que pode ser reaproveitado várias vezes em outro canteiro.

\section{Método de Pesquisa}

O trabalho foi desenvolvido com base na pesquisa de mestrado de Knöner (2014) apoiada pela rede CANTECHIS/FINEP. A pesquisa tratou de um estudo teórico e experimental, dividido em três etapas:

- A primeira etapa consistiu no estudo sobre a utilização de diferentes sistemas construtivos para aplicação em instalações provisórias, buscando identificar as principais características necessárias para essas estruturas;

- A segunda etapa consistiu no desenvolvimento de um projeto de instalações provisórias em pré-moldado de concreto de forma a agregar vantagens técnicas, econômicas, sociais e ambientais;

- A terceira etapa consistiu na realização de simulações teóricas por meio de ensaios de laboratório e da determinação dos parâmetros técnicos necessários para desenvolvimento do produto.

A fase de montagem e desmontagem do protótipo não foi desenvolvida por Knöner (2014) devido à duração do mestrado ser inferior ao tempo necessário para a elaboração do produto. Este trabalho foca na apresentação sucinta das etapas 2 e 3, que podem ser melhor verificadas no trabalho original.

O Anexo apresenta momentos da montagem do protótipo ocorrida em 2017.

\section{Sistema Proposto de Instalações Provisórias}

O sistema de pré-moldado de um pavimento foi criado inicialmente com propósito da habitação social, visando proporcionar moradias para a classe de baixa renda, com características de simplicidade, rapidez na montagem, viabilidade econômica e resistência. O sistema inicial foi adaptado para obra de instalação provisória atendendo às necessidades de montagem e desmontagem futura dos componentes pré-moldados. 
A Figura 1 mostra a planta da instalação provisória projetada para construção do protótipo, que se trata de um ambiente de escritório, formado por uma sala e um pequeno banheiro. A dimensão externa corresponde a $6 \mathrm{~m}$ de comprimento por $3,5 \mathrm{~m}$ de largura, com uma varanda de 1,5 m. O protótipo conta com as seguintes peças prémoldadas de concreto:

- Montantes ou Pilares: seção 10 x $10 \mathrm{~cm}$ e altura 3,20 m;

- Placas: dimensões $50 \times 100 \mathrm{~cm}$ e espessura $2,5 \mathrm{~cm}$;

- Elemento de fundação (apoio para pilar): dimensões $25 \times 25 \mathrm{~cm}$ e altura $12 \mathrm{~cm}$.

Na planta baixa (Figura 1), percebe-se que as paredes são formadas por placas, colocadas externa e internamente fixadas aos pilares, dotadas de um vão entre elas, que se configura como uma câmara de ar. Esta solução beneficia também a resistência térmica e conforto acústico do sistema construtivo.

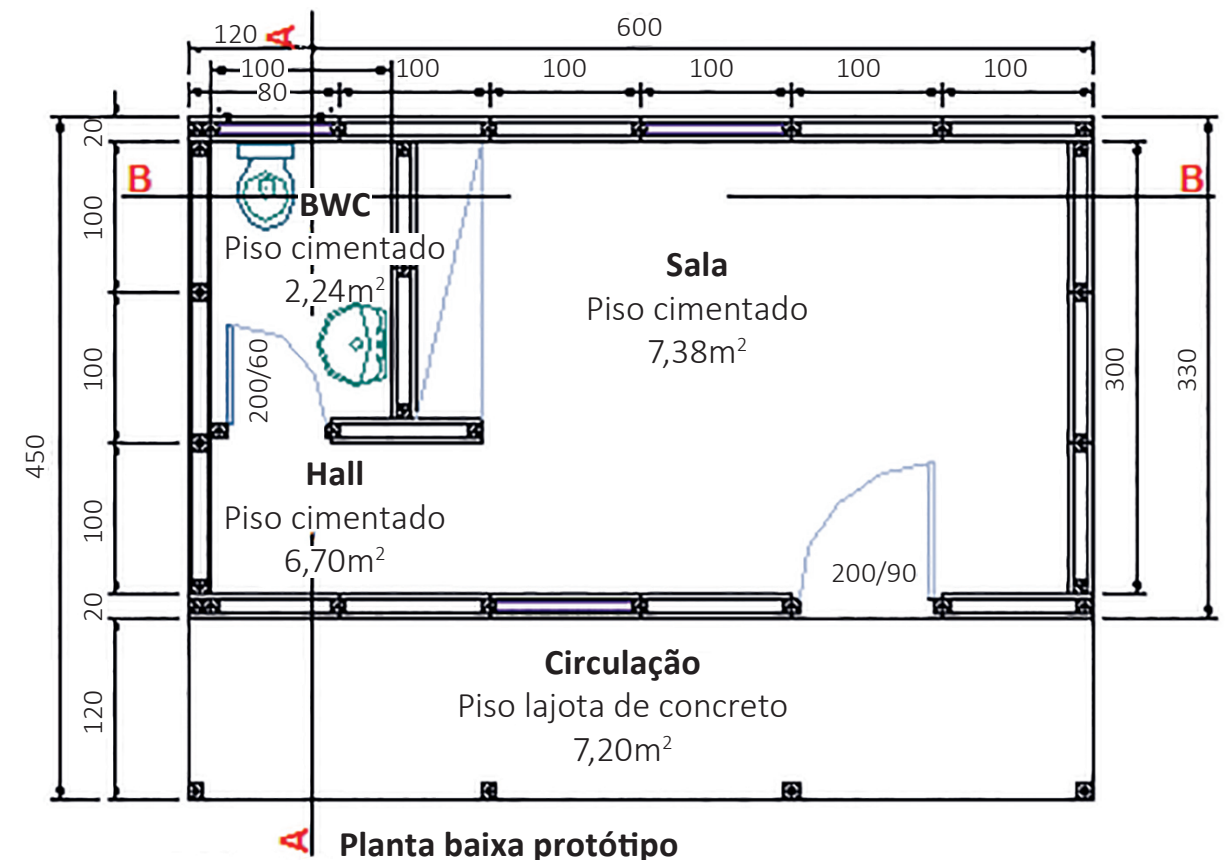

Piso lajota de concreto

$27,18 \mathrm{~m}^{2}$

Figura 1 - Planta baixa do protótipo para instalações provisórias. Fonte: Knöner, 2014.

Na Figura 2, é possível observar as dimensões e a forma de fixação do pilar ou montante sobre o elemento de fundação. O concreto para enchimento da fundação pode ser magro, uma vez que o pilar poderá ser retirado e reutilizado. 


\section{Montante}

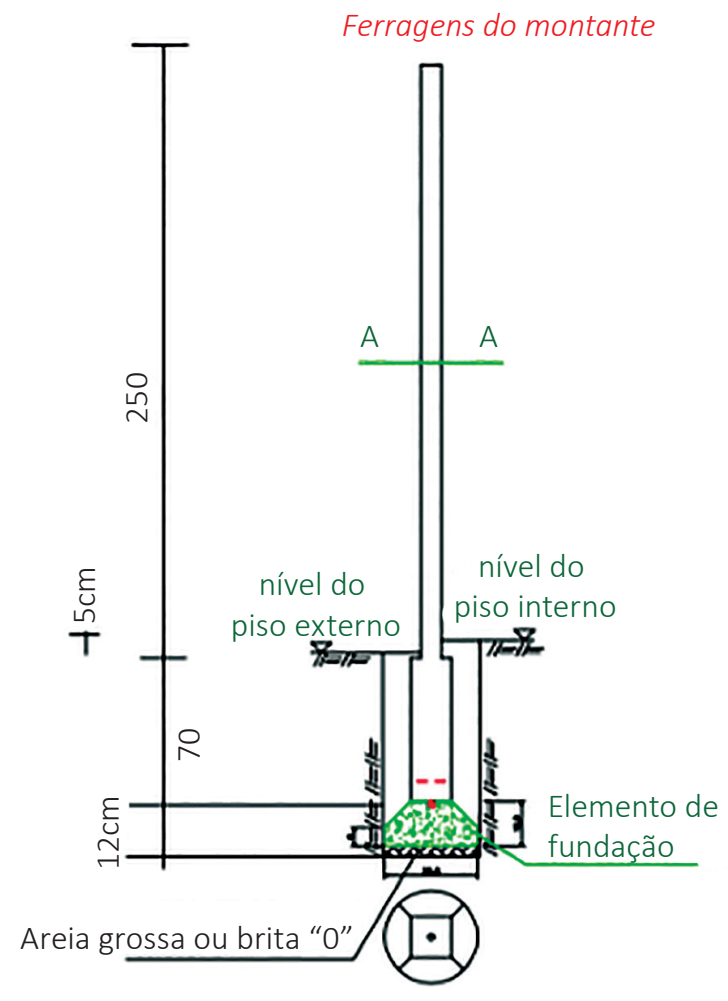

Figura 2 - Detalhe do montante e execução da fundação. Fonte: Knöner, 2014.

As principais características do sistema proposto são relacionadas a seguir:

- A instalação não necessita de fundação direta (blocos ou sapatas) nem possui vigas de baldrames, posto que foi desenvolvida uma peça especial para fixação do pilar na fundação;

- Os componentes dos montantes ou pilares foram feitos em concreto armado e possuem dimensão compatível atendendo o pé direito e a profundidade da fixação em solo;

- As paredes são formadas com duas placas de concreto fixadas externa e internamente nos pilares ou montantes com parafusos e buchas;

- Na parte superior da parede é fixado um perfil metálico tipo "U”, colaborando para a estabilidade das paredes e suporte para a estrutura metálica do telhado;

- Podem ser utilizados diferentes tipos de telhas, sendo a mais indicada a termoacústica; 
- As paredes não precisam ser rebocadas, apenas pintadas. Deve-se utilizar massa de vedação entre as placas que compõem as paredes externas;

- Todos os pontos elétricos - caixa de passagem, interruptores, tomadas são fixados no momento da concretagem das placas. Durante a montagem, as tubulações ficarão embutidas entre as placas. Outra solução possível é a concepção de instalações aparentes que poderão ser montadas após a finalização da estrutura do protótipo;

- Os pontos de água também foram concretados nas placas correspondentes. As tubulações hidráulicas de fornecimento de água potável também são fixadas durante a montagem e ficam entre as placas que compõem as paredes. Outra opção seria também o uso das instalações aparentes;

- Os batentes de porta e janelas encaixam-se entre os montantes e são de fácil colocação. Podem ser pré-moldados, metálicos ou de madeira. No caso estudado, optou-se por esquadrias metálicas para as janelas e madeira para as portas. As janelas devem ser encaixadas e simplesmente confinadas entre dois montantes, sendo necessária sua fixação durante a montagem do protótipo.

A Figura 3 mostra o Corte A-A da instalação provisória, podendo ser identificada a viga metálica de coroamento da estrutura de concreto pré-moldado e o uso previsto da telha termoacústica.

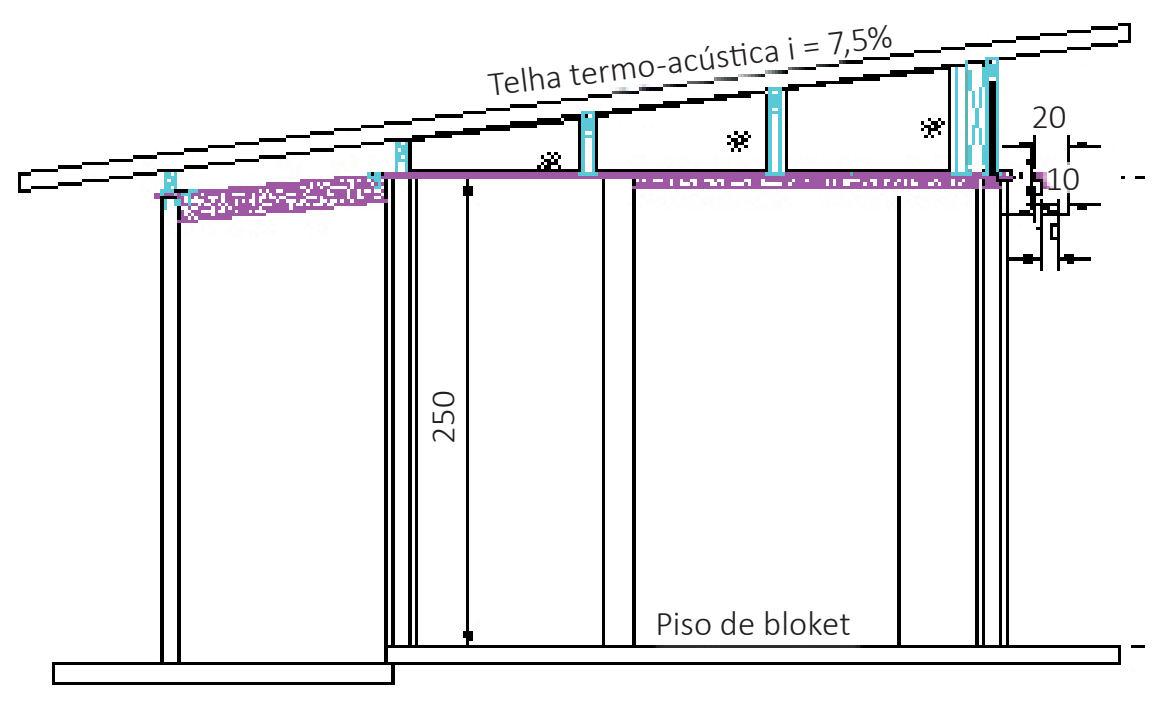

Vista lateral

Figura 3 - Corte A-A do protótipo para instalações provisórias. Fonte: Knöner, 2014. 
A Figura 4 mostra a perspectiva do protótipo de acordo com o projeto concebido.

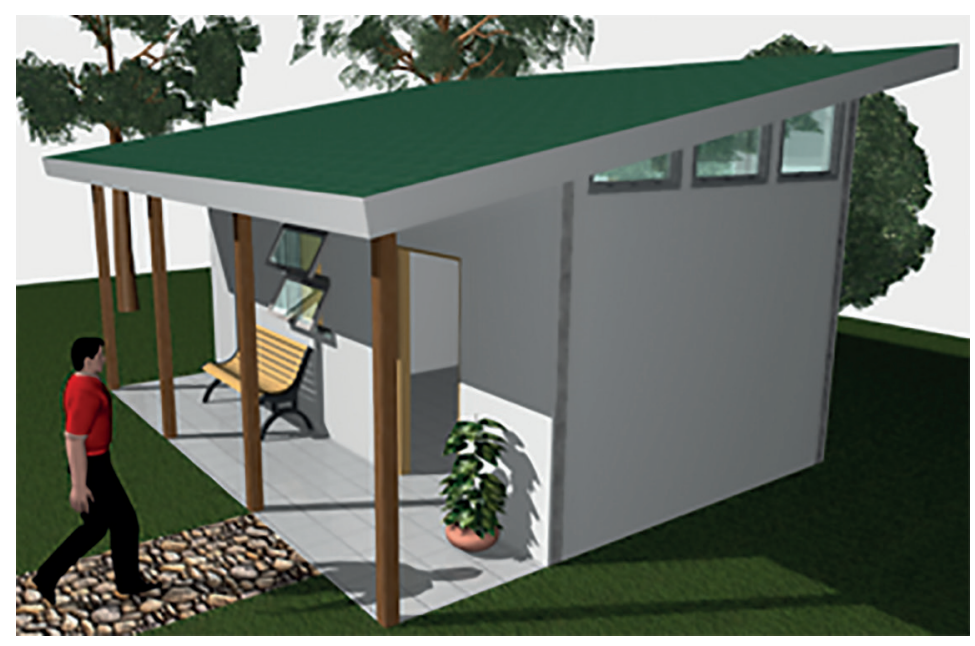

Figura 4 - Perspectiva do protótipo para instalações provisórias. Fonte: Knöner, 2014.

A partir da concepção do produto, procedeu-se ao cálculo e simulação matemática dos componentes do protótipo. Em seguida, foram realizados os testes experimentais nos componentes de concreto pré-moldado - pilares e placas - para posterior liberação da produção necessária para montagem do protótipo. Os demais elementos do sistema não foram ensaiados, pois o foco da pesquisa foi a análise do sistema construtivo denominado "parede".

\section{Confecção das Peças de Concreto do Sistema "Parede"}

As peças de concreto que compõem o fechamento das paredes da obra foram produzidas em concreto convencional, conforme descrito a seguir.

\subsection{Placas de Concreto}

Constituídas por concreto, cimento, areia, brita zero e tela com malha de 1-1/2", diâmetro médio 0,66 mm, $\mathrm{f}_{\mathrm{yk}}=320 \mathrm{MPa}$, concreto de resistência característica $\mathrm{fck}=20 \mathrm{MPa}$, com as dimensões de $1,0 \mathrm{~m} \times 0,50 \mathrm{~m} \times 2,5 \mathrm{~cm}$ e peso médio de $30 \mathrm{~kg}$ por placa. Para confecção das placas, foi concebida a forma metálica mostrada na Figura 5. Deve ser passado um desmoldante que facilite a desforma da placa. A peça é concretada, vibrada e posta rigorosamente em nível, garantindo uma boa modelagem e cura. 


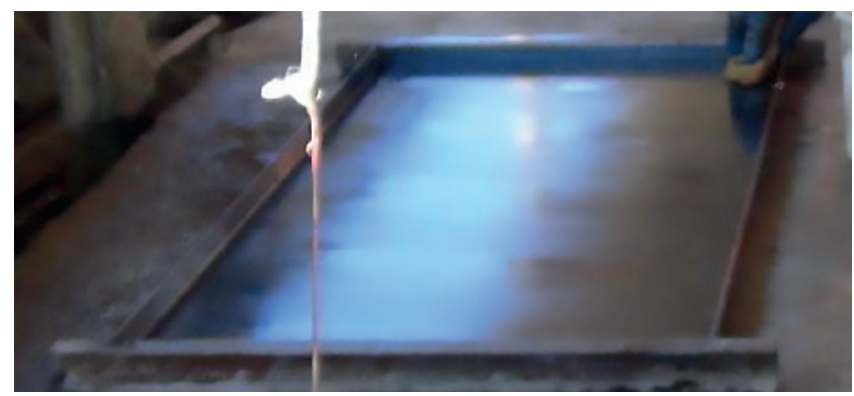

Figura 5 - Vista da forma metálica para confecção das placas de concreto pré-moldado. Fonte: Knöner, 2014.

Após 12 h da concretagem, a placa pode ser desmoldada e permanecer curando. As formas metálicas podem ser liberadas para concretagem da próxima placa.

\subsection{Montantes ou Pilares}

Para fabricação dos montantes, também se utilizou de uma forma metálica, de desmoldante e colocação de armaduras. A Figura 6 mostra a forma metálica do montante e a armadura do pilar posicionada ao lado. Foi dimensionado o uso de 4 ferros de diâmetro de 6,3 mm, CA 50, e estribos de diâmetro de 4,2 mm, CA 60, com espaçamento a cada $12 \mathrm{~cm}$. Utilizou-se o mesmo concreto das placas e o peso dos montantes ficou em torno de $75 \mathrm{Kg}$.

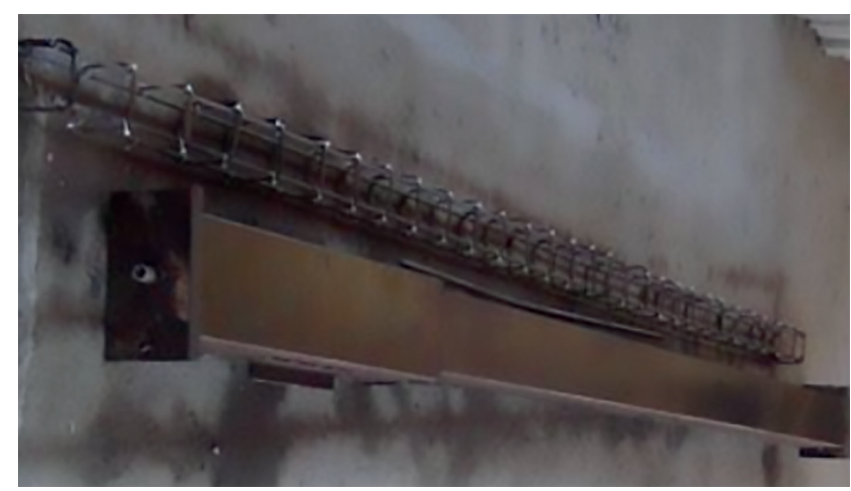

Figura 6 - Detalhe da forma e armadura dos montantes estruturais. Fonte: Knöner, 2014.

As formas foram preparadas, niveladas e limpas antes que fosse passado o desmoldante. As armaduras devem ser conferidas, garantindo-se um cobrimento mínimo das peças. Da mesma forma, a peça foi concretada, vibrada e posta rigorosamente em nível, garantindo uma boa modelagem e cura. 


\section{Análises Teóricas}

\subsection{Resistência ao Fogo}

De acordo com a NBR 5.627 (ABNT, 1980), o critério básico de classificação das edificações em relação à resistência ao fogo é determinado em função do tempo de duração que um elemento estrutural deve resistir.

No caso dos painéis, a análise mais importante é a da transmissão de calor através da espessura do componente. Raramente o cobrimento das armaduras tem a função de absorver as tensões das etapas de desforma e transporte, sendo um fator predominante na determinação da resistência ao fogo dos painéis (Precast Concrete Institute (PCI), 1989).

Segundo NBR 14.432 (ABNT, 2001), a determinação do TRRF (Tempo requerido de resistência ao fogo) é em função do tipo de ocupação da edificação e da sua altura. A mesma norma menciona que "estão isentas dos requisitos de resistência ao fogo estabelecidos nesta Norma as edificações cuja área total seja menor ou igual a $750 \mathrm{~m}^{2 \prime}$.

Entretanto, optou-se por analisar o parâmetro tendo por base a norma do PCl (1989) para painéis de concreto. Nesse caso, foi considerada a espessura da placa aproximadamente igual a $10 \mathrm{~cm}$ (2 polegadas), sem considerar a camada de ar entre as mesmas, e o tipo de concreto como leve (lightweight concrete). Com o ábaco disponível na publicação, obtém-se o resultado identificado na Figura 7. Ou seja, utilizando gráfico do PCI (1989) foi determinado o tempo de 50 minutos de resistência ao fogo.

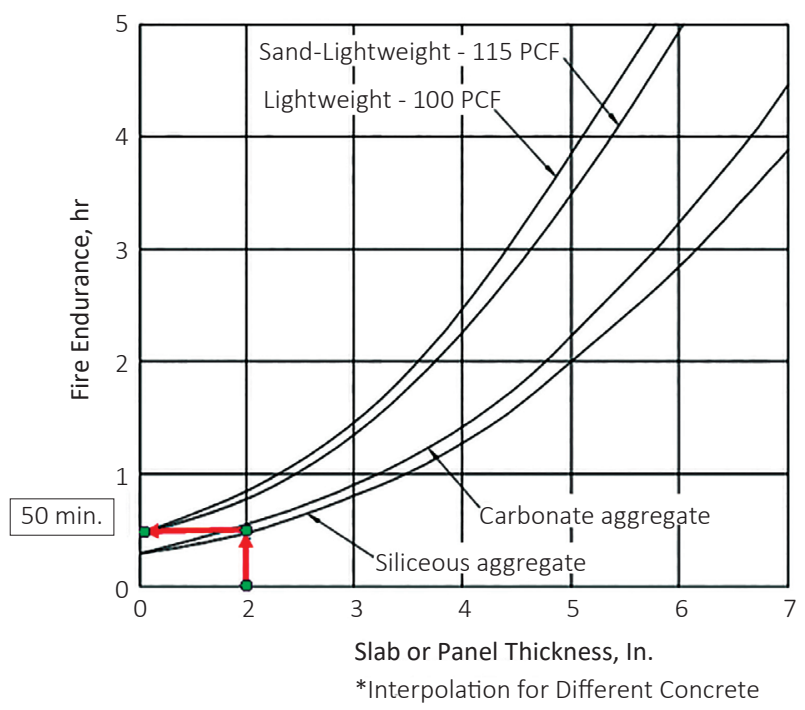

Figura 7 - Gráfico para determinação do tempo de transmissão de calor em concreto prémoldado considerando a espessura da placa. Fonte: PCl, 1989. 


\subsection{Desempenho Térmico}

Segundo NBR 15.575 (ABNT, 2013), o objetivo é verificar se a transmitância térmica e capacidade térmica do sistema "parede" proporcionam desempenho térmico mínimo conforme estabelecido para cada zona bioclimática do Brasil, de acordo com ABNT NBR 15.220 (ABNT, 2008).

Considerando a região de São Carlos, denominada região 4 devido a condição do clima da cidade, a NBR 15.220 (ABNT, 2008) estabelece que as paredes devem ser pesadas e as coberturas devem ser leves. As paredes pesadas, conforme Tabela C.2 da referida norma, devem ter transmitância térmica $(U)$ menor ou igual a 2,2W/m2.k, atraso térmico $(\phi)$ maior ou igual a $6,5 \mathrm{~h}$ e fator solar (FSo) menor ou igual a 3,5 \%.

Como se sabe, a área total do protótipo é de $27 \mathrm{~m}^{2}$ e o pé direito médio é de $\mathrm{h}=2,80 \mathrm{~m}$, sabe-se também que as paredes possuem duas placas, com espessura de $2,5 \mathrm{~cm}$ cada. A câmara de ar de $10 \mathrm{~cm}$ entre as placas não é configurada como opção entre as tipologias de vedações. A Figura 8 mostra os parâmetros que são considerados na análise deste requisito.

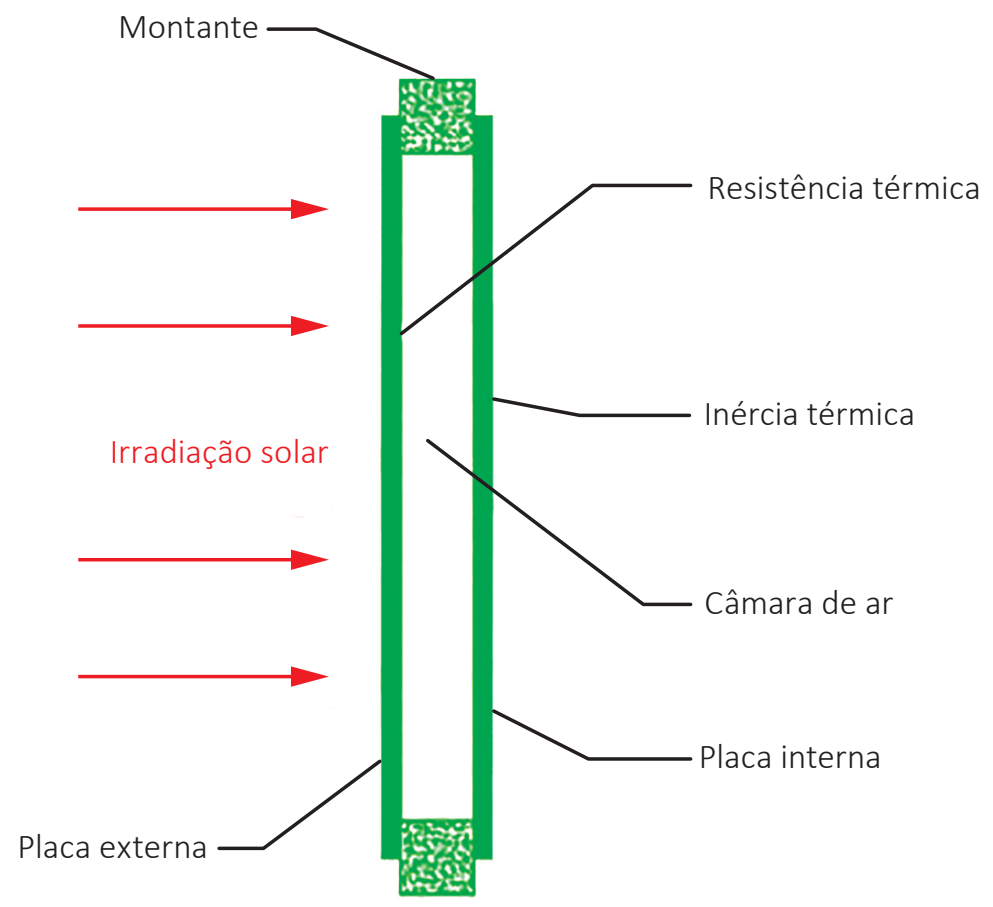

Figura 8 - Esquema do sistema "parede" em estudo quanto aos aspectos de desempenho térmico. Fonte: Knöner, 2014. 
Knöner (2014) verificou os cálculos de acordo com as normas, mas os valores encontrados para a cidade de São Carlos não as atenderam, pois o atraso térmico obtido numericamente foi de 2,2 h, quando deveria ser de 6,5 h.

Assim, entende-se que a análise foi prejudicada, já que não foi possível considerar a câmara de ar. Mas a espessura da placa pode ser ajustada em função da região bioclimática brasileira, aumentando ou diminuindo a inércia térmica.

Como exemplificação, a Figura 9 mostra que as propriedades de inércia térmica do componente podem ser variadas para atingir o nível de desempenho desejado, em qualquer parte ou região com diferentes climas (FIB, 2012).
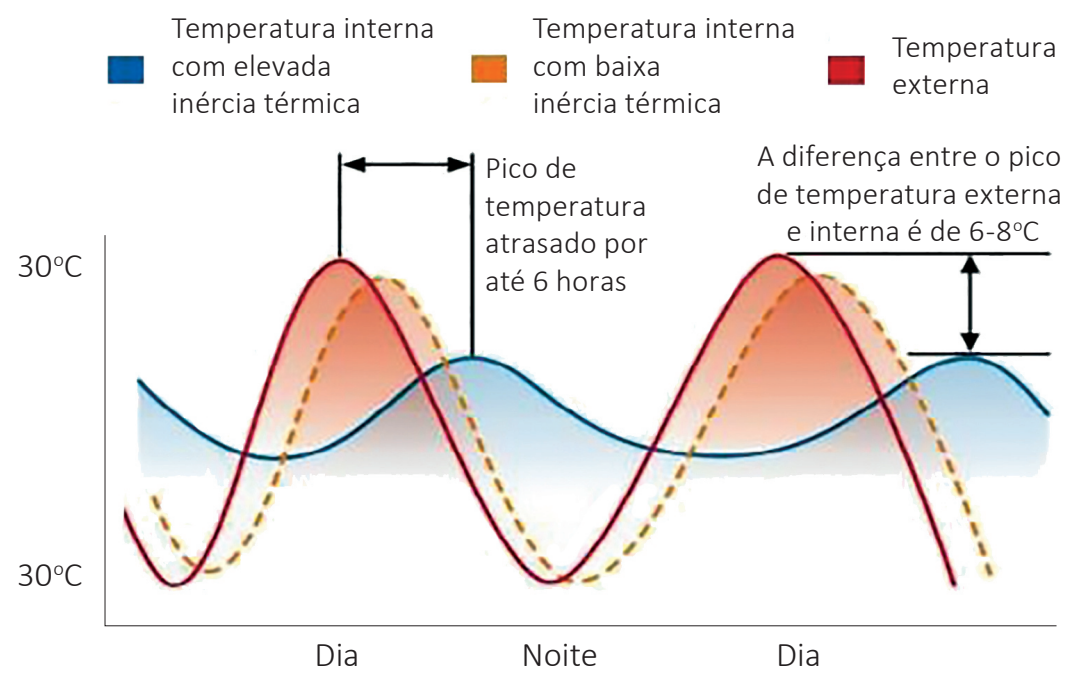

Figura 9 - Atraso da onda de calor devido à massa térmica do concreto. Fonte: FIB, 2012.

Assim, torna-se importante que essas variáveis sejam medidas em campo após a montagem do protótipo para comprovar as vantagens do sistema proposto. O resultado da elevada massa térmica tem influências na redução significativa do consumo de energia, sem necessidade de aquecimento ou resfriamento de forma artificial.

\section{Ensaios Experimentais em Laboratório}

\subsection{Ensaios de Compressão Centrada}

Foram realizados ensaios de compressão centrada nos montantes para aferir a capacidade resistente deles. A carga prevista no montante de concreto após levantamento das cargas existentes pode ser verificada na Tabela 1. 
Tabela 1 - Levantamento das cargas existentes no montante mais desfavorável.

\begin{tabular}{llll}
\hline Peça & Dimensão & Peso específico & Carga \\
\hline Peso próprio do pilar & $0,10 \times 0,10 \times 3,20$ & $2400 \mathrm{~kg} / \mathrm{m}^{3}$ & $0,80 \mathrm{KN}$ \\
\hline $\begin{array}{l}\text { Peso próprio das placas } \\
\text { (considerou-se a fixação de } 12 \text { placas } \\
\text { em cada pilar) }\end{array}$ & $0,025 \times 0,5 \times 1,0$ & $2400 \mathrm{~kg} / \mathrm{m}^{3}$ & $3,60 \mathrm{kN}$ \\
\hline $\begin{array}{l}\text { Cobertura metálica } \\
\text { (considerou-se a carga distribuída em }\end{array}$ & $27,18 \mathrm{~m}^{2}$ & & \\
32 pilares) & & $21,92 \mathrm{~kg} / \mathrm{m}^{2}$ & $0,19 \mathrm{kN}$ \\
\hline $\begin{array}{l}\text { Telha termoacústica: } \\
\text { (considerou-se a carga distribuída em }\end{array}$ & $28 \mathrm{~m}^{2}$ & & \\
32 pilares) & & $6,0 \mathrm{kgf} / \mathrm{m}^{2}$ & $0,06 \mathrm{kN}$ \\
\hline \begin{tabular}{l}
$\Sigma$ cargas verticais: $=$ \\
\hline
\end{tabular} & & & $4,65 \mathrm{kN}$ \\
\hline
\end{tabular}

Fonte: Knöner, 2014.

Considerando-se a carga máxima no montante majorada encontrou-se uma seção de armadura (As) igual a $0,15 \mathrm{~cm}^{2}$, sendo adotado $A s=1,27 \mathrm{~cm}^{2}$, que correspondeu a quatro ferros de diâmetro igual a 6,3 $\mathrm{mm}$. Considerou-se, no cálculo da armadura transversal, estribos de 4,2 mm com espaçamento de $12 \mathrm{~cm}$. Foi verificada e atendida a excentricidade máxima do montante para que resista uma compressão no concreto de 171 kN (valor da carga crítica de flambagem do montante). Foram ensaiados três montantes com a aplicação de força centrada até a sua ruptura, como pode ser observado na Figura 10.
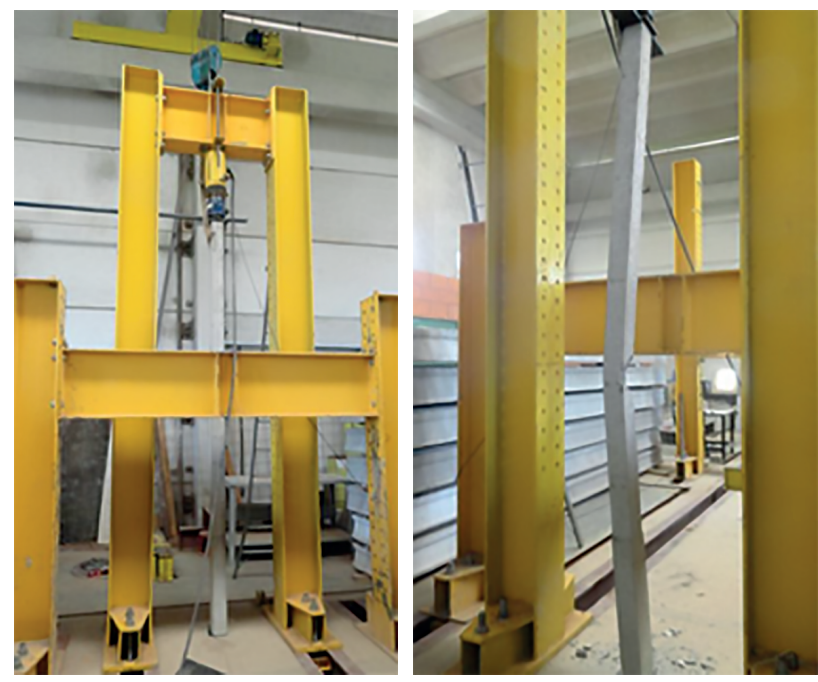

Figura 10 - Ensaio de compressão axial dos montantes. Fonte: Knöner (2014). 
Foram utilizados os equipamentos disponíveis no Laboratório de Pré-moldados (NETPRE) da UFSCar, principalmente a prensa hidráulica de 1000 kN. Os pilares se romperam devido à flambagem, resistindo à força axial esperada, conforme Tabela 2.

Tabela 2 - Resultados dos ensaios de compressão axial dos pilares.

\begin{tabular}{ll}
\hline Montante Ensaiado & Pu. exp. (kN) \\
\hline Montante 01 & 131,12 \\
\hline Montante 02 & 164,21 \\
\hline Montante 03 & 195,71 \\
\hline Média & 163,68 \\
\hline
\end{tabular}

Pu. exp.: Máxima capacidade obtida por meio de ensaio.

Fonte: Knöner, 2014.

Visto que a carga máxima verificada no montante que recebeu maior carga foi de $55 \mathrm{kN}$, com coeficiente de segurança mínimo verificado de $\gamma=2,38$, o pilar atendeu às necessidades de uso.

\subsection{Ensaio de Flexão da Placa de Concreto que Compõe a Parede}

Inicialmente foram avaliadas as placas pré-moldadas por meio de ensaios de flexão. A carga máxima prevista na placa foi de $1,20 \mathrm{kN}$, distribuída em dois pontos, com momento correspondente de $0,4 \mathrm{kN}$.m, conforme Figura 11. Foram considerados 31 diâmetros de armadura de tela, no sentido longitudinal da placa, cada diâmetro corresponde a $\mathrm{d}=0,50 \mathrm{~mm}$ e cada fio possui uma área de $\mathrm{A}=0,05 \mathrm{~cm}^{2}$. Somando a área total da seção da armadura encontra-se o valor de $A s=1,7 \mathrm{~cm}^{2}$, sendo a espessura da placa igual a 2,5 cm, largura de $50 \mathrm{~cm}$ e comprimento de $100 \mathrm{~cm}$, conforme já mencionado.

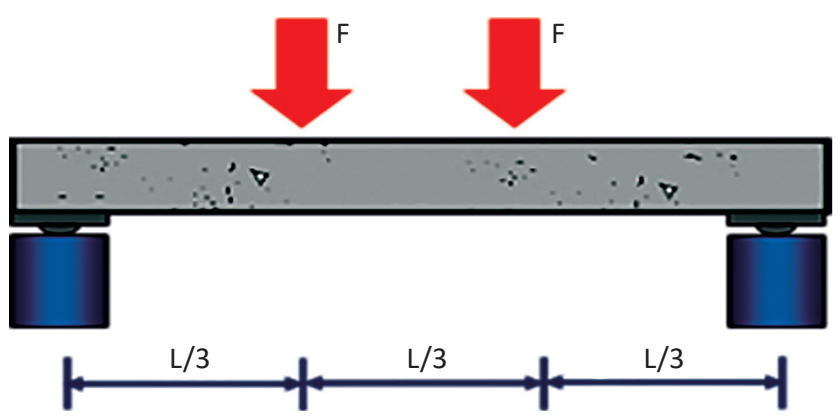

Figura 11 - Esquema de ensaio de flexão em placa pré-moldada. Fonte: Knöner, 2014. 
Com os ensaios, pode-se concluir que as placas pré-moldadas suportaram um momento máximo no meio do vão de $0,41 \mathrm{kN}$.m, referente à aplicação de uma força de 1,66 kN, dividida em dois pontos, conforme Figura 12. Tal resultado atende a NBR 15.575 - Edificações Habitacionais - Desempenho (ABNT, 2013).
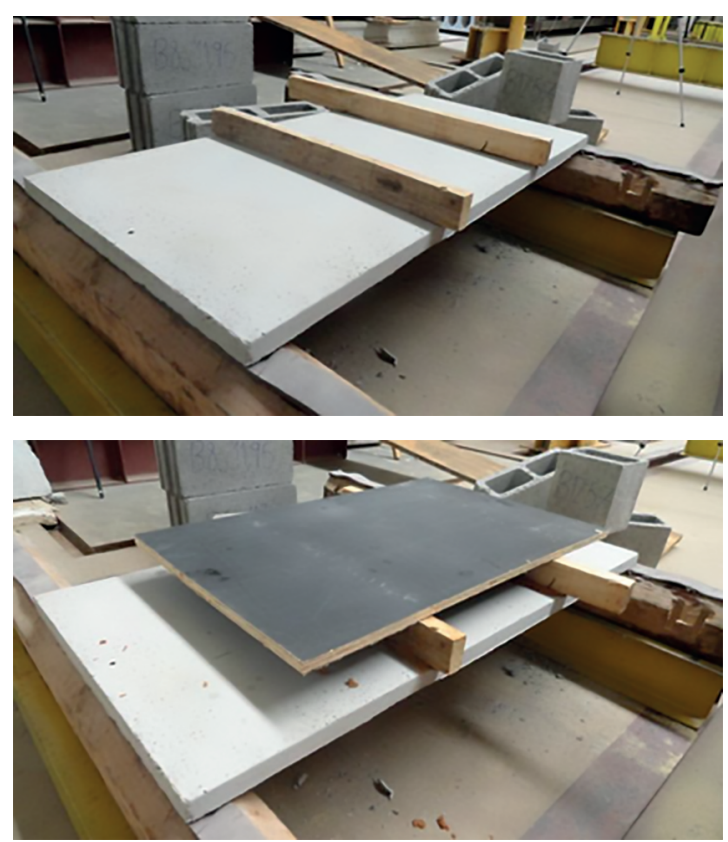

Figura 12 - Esquema de montagem das placas a serem ensaiadas. Fonte: Knöner, 2014.

Os resultados dos ensaios de flexão das placas pré-moldadas podem ser visualizados na Tabela 3.

Tabela 3 - Resultados dos ensaios de flexão nas placas pré-moldadas.

\begin{tabular}{lll}
\hline Peça Ensaiada & $P_{\text {u,exp }}$ & $M_{\text {vão }}$ \\
\cline { 2 - 3 } & $(\mathrm{kN})$ & $(\mathrm{kN} \cdot \mathrm{m})$ \\
\hline Placa 01 & 1,70 & 0,425 \\
\hline Placa 02 & 1,59 & 0,40 \\
\hline Placa 03 & 1,59 & 0,40 \\
\hline Placa 04 & 1,76 & 0,44 \\
\hline Média & 1,66 & 0,42 \\
\hline
\end{tabular}

$\mathrm{P}_{\text {u,exp }}$ : Máxima capacidade obtida por meio de ensaio; $\mathrm{M}_{\text {vão }}$ : momento no meio do vão.

Fonte: Knöner, 2014. 


\subsection{Ensaio de Carga Suspensa}

Inicialmente foi montado um sistema "parede" composto por dois montantes e seis placas aparafusadas de um lado apenas. A Figura 13 mostra que, no laboratório, os montantes foram dispostos no solo e as placas aparafusadas e fixadas com buchas de PVC na horizontal. Após a fixação de todas as placas em seus respectivos montantes, resultou um painel que foi erguido no local como painel tipo tilt-up.
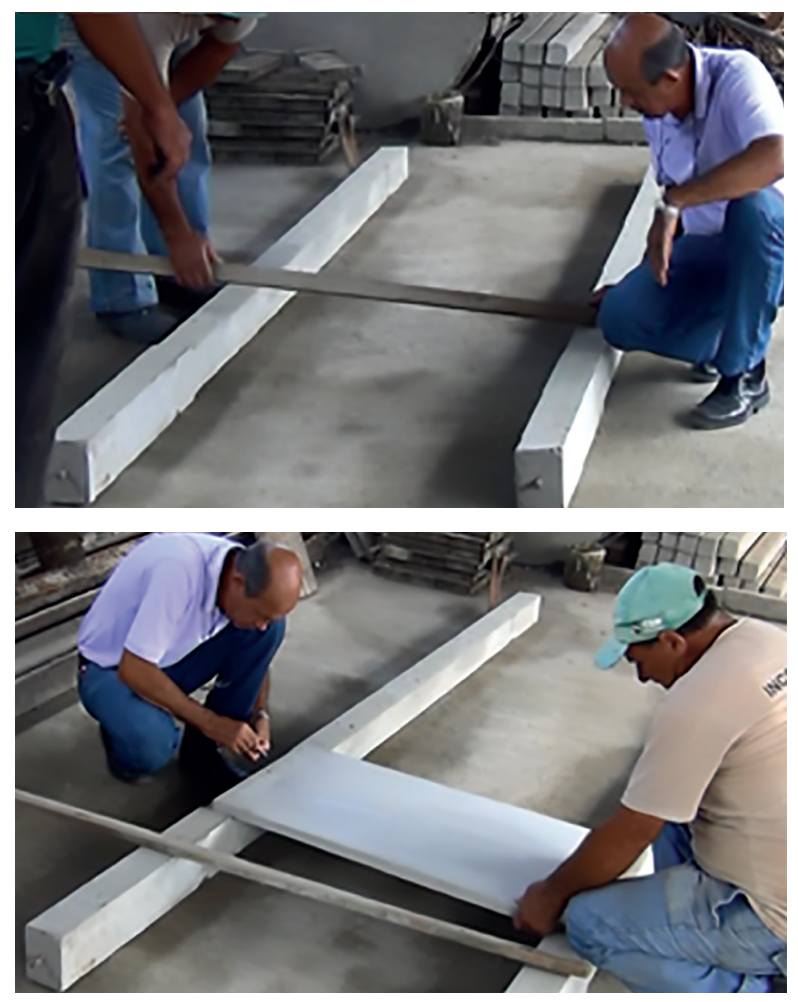

Figura 13 - Fixação das placas nos montante, montagem de um painel no solo. Fonte: Knöner, 2014.

Os ensaios a seguir consistem em submeter o sistema formado por montantes e placas aos esforços de momento fletor e de força cortante, por meio de aparelhagem ou dispositivos de carga compatível com a peça que se pretende ensaiar. Na análise da resistência ao ensaio de carga suspensa indicado pela NBR 15.575 - Edificações Habitacionais - Desempenho, parte 4 (ABNT, 2013), foi fixado um suporte em uma face da placa e parafusada com parafuso de $8 \mathrm{~mm}$ de diâmetro e $6 \mathrm{~cm}$ de comprimento, e bucha de PVC, tal como indicado na Figura 14. 


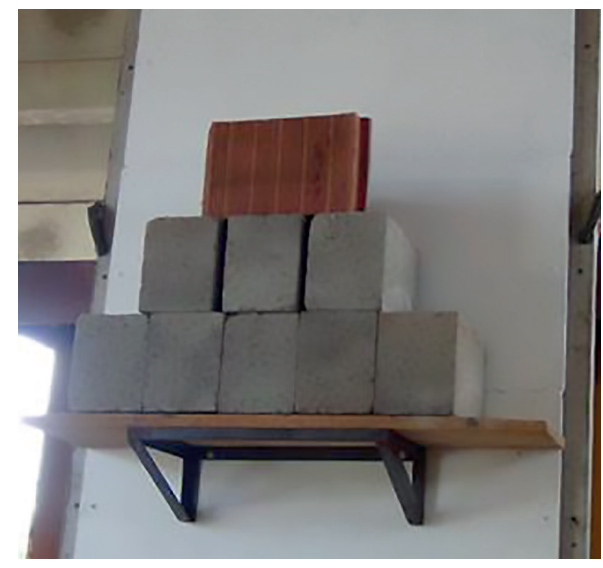

Figura 14 - Ensaio de carga suspensa na parede 1,20 kN período de 24 h. Fonte: Knöner, 2014.

O ensaio foi realizado com os dispositivos em laboratório, reproduzindo as situações previstas na NBR 15.575 - Edificações Habitacionais - Desempenho, sendo aplicada a carga em patamares de aproximadamente de $50 \mathrm{~N}$ e sem golpes, aguardando intervalo aproximado de 3 minutos entre os patamares de carregamento.

De início, o suporte foi carregado atingindo 1,0 kN e permaneceu com essa carga por $24 \mathrm{~h}$, sendo observado o deslocamento da placa em $\mathrm{dh}=1,0 \mathrm{~mm}$. O carregamento foi ampliado para 1,2 kN e, permanecendo por mais $24 \mathrm{~h}$, o deslocamento passou para $\mathrm{dh}=1,50 \mathrm{~mm}$. A carga ficou exposta por vários dias e não foram observadas alterações nos resultados.

Algumas observações:

- O deslocamento horizontal dh =1,5 mm foi observado na ligação do parafuso com a bucha de PVC;

- Não houve movimentação do sistema além do deslocamento verificado por relógio de deslocamento;

- Não houve fissuras nem movimentações;

- O sistema de fixação obedeceu rigorosamente a NBR 15.575 - Edificações Habitacionais - Desempenho, parte 4 (ABNT, 2013);

- Não houve restrições do fabricante do suporte para as cargas preparadas.

\subsection{Ensaio de Estanqueidade à Água}

A diretriz de ensaio consistiu em submeter, durante um tempo determinando, a face externa de um corpo de prova do sistema montado a uma vazão de água, criando uma película homogênea e contínua, com aplicação simultânea de uma pressão pneumática 
sobre essa face, seguindo as orientações da NBR 15.575 - Edificações Habitacionais Desempenho, parte 4 (ABNT, 2013). Com isso, espera-se que as águas das chuvas não venham a prejudicar o interior do ambiente de trabalho, com umidade ou infiltrações.

O corpo de prova foi constituído pelo sistema "parede", formada por placa externa de concreto com espessura de $2,50 \mathrm{~cm}$, concentrando a análise em duas placas, das quais uma pintada e a outra sem pintura, conforme Figura 15.

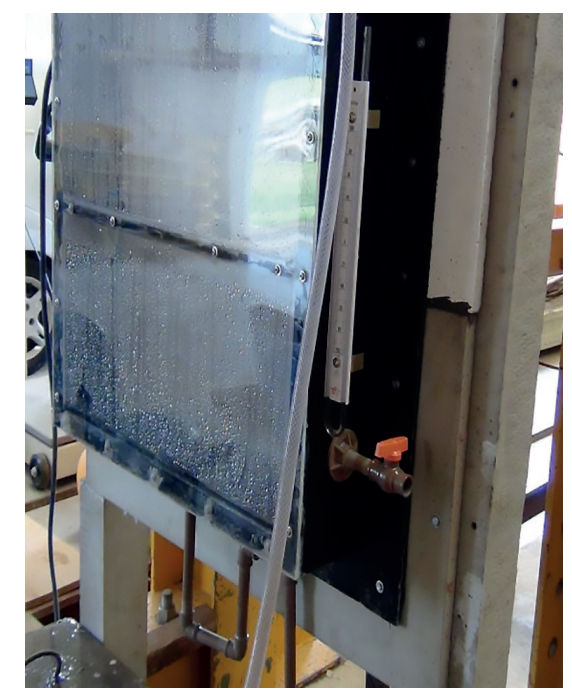

Figura 15 - Esquema de montagem do corpo de prova para ensaio. Fonte: Knöner, 2014.

Após $7 \mathrm{~h}$ de ensaio, apareceram pequenas manchas de água na face oposta da placa de $2,5 \mathrm{~cm}$ de espessura entre as placas.

\subsection{Ensaio de Corpo Duro}

A norma NBR 15.575 - Edificações Habitacionais - Desempenho, parte 4 (ABNT, 2013), estabelece um método para verificação da resistência do sistema de parede à deformação provocada pelo impacto de corpo duro. O ensaio consistiu na liberação pendural, em repouso, de massa conhecida a uma altura determinada. A aparelhagem consistiu em:

- Um corpo de impacto com forma (esfera) e massa (1 kg) conforme estabelecido na norma; NBR 15.575 - Edificações Habitacionais - Desempenho (ABNT, 2013);

- Dispositivo para medição dos deslocamentos com resolução de 0,1 mm.

O corpo de prova representou fielmente as condições do projeto, tipos de apoios e vinculações. O ensaio foi realizado no interior do NETPRE, utilizando um sistema "parede" em tamanho real. 
A execução do ensaio visou suspender por um cabo o impactador, liberando-o em movimento pendural, gerando a energia de impacto indicado na Tabela 4. Os impactos foram aplicados em pontos aleatórios e distintos, conforme Figura 16, com altura constante de $h=1,0 \mathrm{~m}$ para todos os lançamentos.

Tabela 4 - Representação e resultados dos impactos realizados sobre a placa.

\begin{tabular}{lllllllllll}
\hline Parâmetro por ponto $^{\circ}$ & 1 & 2 & 3 & 4 & 5 & 6 & 7 & 8 & 9 & 10 \\
\hline Dh $(\mathrm{mm})$ & 1,33 & 1,34 & 1,33 & 1,33 & 1,34 & 1,35 & 1,35 & 1,35 & 1,35 & 1,35 \\
\hline Ap $(\mathrm{mm})$ & 0,2 & 0,2 & 0,2 & 0,1 & 0,1 & 0,1 & 0,1 & 0,1 & 0,1 & 0,2 \\
\hline Daf $(\mathrm{mm})$ & 1,1 & 1,0 & 1,11 & 1,2 & 1,1 & 1,1 & 1,0 & 1,1 & 1,1 & 1,0 \\
\hline
\end{tabular}

Dh - Deslocamento horizontal medido no lado oposto da placa;

Ap - Afundamento na parede da placa de concreto;

Daf-Diâmetro do afundamento na placa.

Fonte: Knöner, 2014.

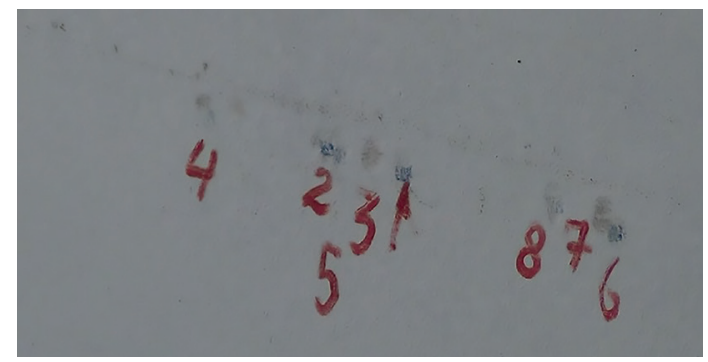

Figura 16 - Local nas placas dos impactos de corpo duro na altura de 1,0 m. Fonte: Knöner, 2014.

Verificou-se que os resultados atendem à NBR 15.775 (ABNT, 2013) quanto ao desempenho recomendável do sistema em relação à resistência ao impacto de corpo duro nos níveis intermediário e superior, tanto para a vedação externa quanto interna. Com a energia de 10 Joules, não houve rupturas além das marcas. Tal resultado atende a NBR 15.575 - Edificações Habitacionais - Desempenho no nível M (mínimo de aceitação).

\subsection{Ensaio de Corpo Mole}

Este ensaio consistiu no lançamento de um saco de couro com altura de $90 \mathrm{~cm}$ e diâmetro de $35 \mathrm{~cm}$, contendo areia e serragem, que totalizava uma massa de $40 \mathrm{~kg}$, conforme os quesitos da NBR 15.575 - Edificações Habitacionais - Desempenho (ABNT, 2013) e NBR 11.675 (ABNT, 2016). É permitida uma variação de $40 \mathrm{~cm}$ para cima ou para baixo no sistema de pêndulo, constituído de suporte (altura superior a da 
parede), fio de aço para sustentar o saco e sistema para medição dos resultados. Um registro do ensaio pode ser observado na Figura 17, na qual se verifica a placa rompida.

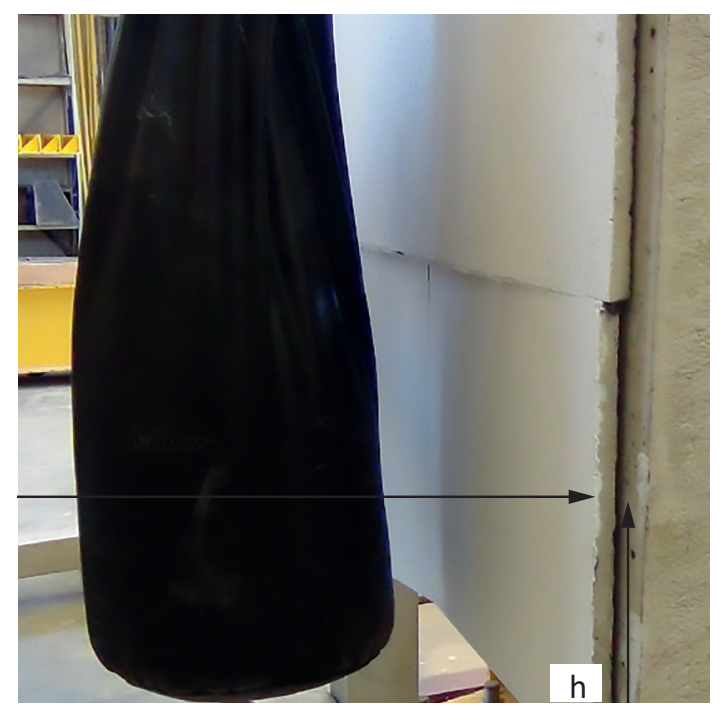

Figura 17 - Ensaio de corpo mole no sistema. Fonte: Knöner, 2014.

Esse ensaio teve como objetivo verificar a resistência do sistema à energia de impacto dos choques acidentais gerados durante a utilização da edificação ou choques provocados por tentativas de intrusões intencionais ou não.

Após o ensaio, verificou-se que a placa com altura mínima de $\mathrm{h}=30 \mathrm{~cm}$ não se rompeu. Com a altura intermediaria ( $h=0,90 \mathrm{~m}$ ), entretanto, a placa rompeu-se, como observado na figura 17. De acordo com a NBR 15.575 - Edificações Habitacionais Desempenho (ABNT, 2013), atendeu o limite inferior.

\section{Análise do Sistema Proposto}

Após a realização dos ensaios e simulação, bem como a consideração das características do sistema construtivo proposto, pode-se verificar as seguintes situações quanto aos parâmetros técnicos:

- Resistência ao fogo: Verificação teórica que o sistema suporta 50 minutos de incêndio, conforme PCl (1989);

- Desempenho Térmico: Possui um atraso térmico de 2,2 h. Não está de acordo com o mínimo desejado para a cidade de São Carlos, que é de 6,5 h; 
- Estrutura: atende as condições de serviço e estado limite último para as solicitações existentes nos componentes dos montantes (compressão) e das placas (flexão);

- Carga suspensa: Atendeu NBR 15.575 - Edificações Habitacionais Desempenho (ABNT, 2013), nível superior "S";

- Estanqueidade: Atendeu NBR 15.575 - Edificações Habitacionais Desempenho (ABNT, 2013), nível superior "S";

- Corpo duro: Atendeu NBR 15.575 - Edificações Habitacionais - Desempenho (ABNT, 2013), nível mínimo "M";

- Corpo mole: Atendeu NBR 15.575 - Edificações Habitacionais - Desempenho (ABNT, 2013), nível mínimo "M".

Em relação aos parâmetros de projeto, foram observadas as seguintes situações:

- Facilidade de Construção: a montagem das peças é possível com apenas dois trabalhadores, não sendo necessário o uso de equipamentos de grande porte. O uso de ferramentas elétricas, como parafusadeira, é recomendado;

- Reaproveitamento: existe a possibilidade de desmonte e transporte para outro lugar sem perdas de materiais e sem gerar resíduos significativos. Os componentes podem ser desmontados com cuidados, remontados e reaproveitados indefinidamente;

- Modulação: o projeto apresenta condições de modulação, facilitando a adaptação de acordo com as características do terreno, espaço disponível e necessidades de produção;

- Custos: o custo inicial maior é referente à fabricação das formas, que podem ser reaproveitadas; o custo de mão de obra é referente aos salários de um pedreiro e de um servente, que trabalharão inicialmente na fabricação e posteriormente na montagem;

- Durabilidade: considerou-se a mesma durabilidade das estruturas de concreto tradicional (mínimo de 50 anos);

- Resíduos: durante a produção dos componentes, pode ser considerado o reaproveitamento de resíduos da construção, mediante ensaios de qualidade dos agregados. Durante a montagem, pode haver perdas decorrentes de quebras e transporte inadequado; deve-se procurar treinar a mão de obra para obter menor desperdício. 


\section{Conclusões}

O sistema proposto mostrou ser simplificado do ponto de vista do projeto, sendo composto basicamente por montantes e placas separadas por uma camada de ar, isolando a camada interna da externa. A fixação das placas é simplificada, podendo ser facilmente desconectadas, em caso de manutenção ou remontagem.

As análises e ensaios realizados colaboraram para afirmar que o protótipo idealizado é viável e possui diversas vantagens em relação às soluções improvisadas comumente utilizadas em canteiros de obras. O uso de soluções pré-fabricadas aumenta a sustentabilidade, em termos ambientais, econômicos e sociais, além de melhorar as condições de trabalho.

Ressalta-se novamente que as normas consultadas não fazem referências às instalações provisórias. Entende-se que é necessário ir além do que exige a NR-18 Condições e meio ambiente de trabalho na indústria da construção (BRASIL, 2015) em relação às áreas de vivência, incorporando requisitos de desempenho do edifício. Considera-se importante que sejam propostos quesitos para as edificações provisórias, tal como relacionado pela NBR 15.575 - Edificações Habitacionais - Desempenho (ABNT, 2013), de forma que sejam garantidas as condições de sustentabilidade das instalações provisórias de canteiro de obra.

Foi possível concluir que o sistema construtivo proposto pode evoluir tecnologicamente e apresentar soluções diferenciadas conforme as necessidades dos empreendimentos e da cadeia produtiva na construção civil. Este trabalho procurou apresentar um resumo da viabilidade e necessidade de projetar as instalações das áreas de vivência em canteiro de obras, visando também ao conforto e à saúde do trabalhador.

\section{Referências}

ABNT. Associação Brasileira de Normas Técnicas. NBR 11.675 - Divisórias leves internas moduladas - Verificação da resistência aos impactos. 2016. 7p. Rio de Janeiro, Brasil.

ABNT. Associação Brasileira de Normas Técnicas. NBR 12.284 - Área de Vivência em Canteiros de Obra. Procedimento. 1991. 14p. Rio de Janeiro, Brasil.

ABNT. Associação Brasileira de Normas Técnicas. NBR 14.432 - Exigências de resistência ao fogo de elementos construtivos de edificações - Procedimento. 2001. 15p. Rio de Janeiro, Brasil.

ABNT. Associação Brasileira de Normas Técnicas. NBR 15.220 - Desempenho térmico de edificações. 2008. Rio de Janeiro, Brasil.

ABNT. Associação Brasileira de Normas Técnicas. NBR 15.575 - Edificações Habitacionais Desempenho. 2013. Rio de Janeiro, Brasil. 
ABNT. Associação Brasileira de Normas Técnicas. NBR 5.627 - Exigências particulares das obras de concreto armado e protendido em relação à resistência ao fogo. 1980. Rio de Janeiro, Brasil. (cancelada)

BRASIL. Ministério do Trabalho e Emprego. Norma Regulamentadora 18 (NR-18): Condições e Meio Ambiente de Trabalho na Indústria da Construção. 2015. Disponível em: http://trabalho.gov.br/index.php/seguranca-e-saude-no-trabalho/normatizacao/normasregulamentadoras. Acesso em: nov. 2016.

DIAS, C.M.; SERRA, S.M.B. Overview of Industrialized Technological Solutions for Temporary Facilities in Construction Sites. 2013. In: Portugal Sustainable Buildings (SB13). Proceedings... Guimarães, Portugal, 2013.

FIB. Federation Internationale Du Beton. Guide to Good Practice: Precast Insulated Sandwich Panels. 2012. Commission 6 - Task Group T 6.11.

KNÖNER, N. Sistema pré-fabricado para aplicação em construções provisórias de canteiros de obra. 2014. 147f. Dissertação (Mestrado em Estruturas e Construção Civil) Universidade Federal de São Carlos, São Carlos, SP.

PCI. Precast Concrete Institute. Design for Fire Resistance of Precast Prestressed Concrete. 1989. 2nd ed. 93p. Disponível em: http://kerkstra.com/uploads/resources/MNL-124-89_ Fire_Resistance.pdf. Acesso em: dez. 2016.

PREFACC. Edificações em Concreto Celular. 1992. Disponível em: http://www.prefacc.com. br/. Acesso em: dez. 2016.

SERRA, S.M.B.; FERREIRA, M.A.; PIGOZZO, B.N. Evolução dos pré-fabricados de concreto. In: 1. Encontro Nacional de Pesquisa-Projeto-Produção em Concreto Pré-moldado, Anais... 2005, USP, São Carlos - SP. v. 1. p. 1-10.

VAN ACHER, A. Manual de Sistemas Pré-fabricados de Concreto. 2002. Tradução: FERREIRA, M.A. 2003. 129f. Disponível em: <http://www.ft.unicamp.br/ cicolin/ST\%20725\%20A/mpf. pdf>. Acesso em: dez. 2016. 


\section{Anexo}

\section{Registro da montagem do protótipo para instalação provisória em pré-moldado de concreto para canteiros de obra}

Local: campus da UFSCar, São Carlos, SP

Período da montagem: fevereiro a maio de 2017

Empresa contratada: Fragalli Engenharia Ltda.

Convenente: Fundação de Apoio Institucional (FAI/UFSCar)

Projeto e responsável técnico: engenheiro civil Nery Knöner

Fotos e acompanhamento: profa. Sheyla Mara Baptista Serra e engenheiro civil José Luis Morelli

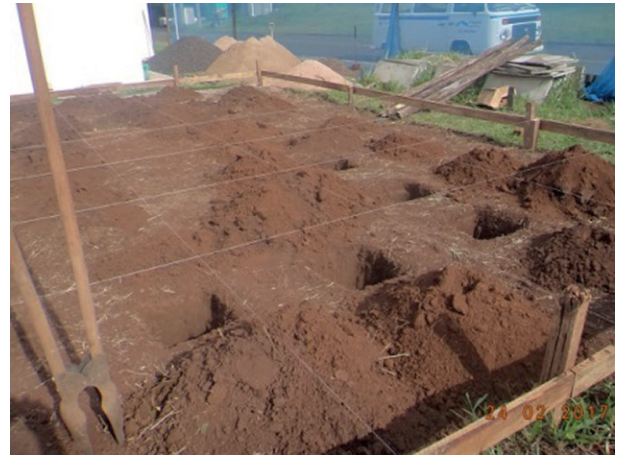

Figura 1 - Vista da locação dos furos referentes aos pilares da instalação provisória.

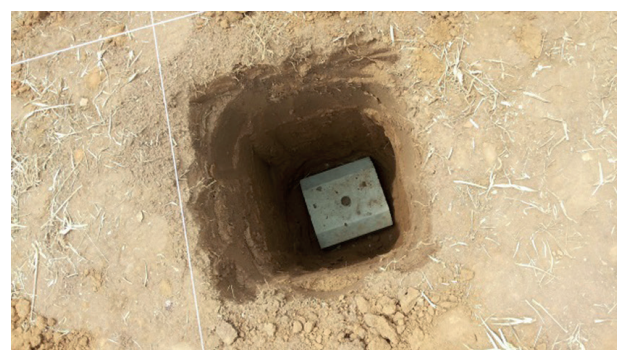

Figura 2 - Elemento de concreto para fixação do pilar.

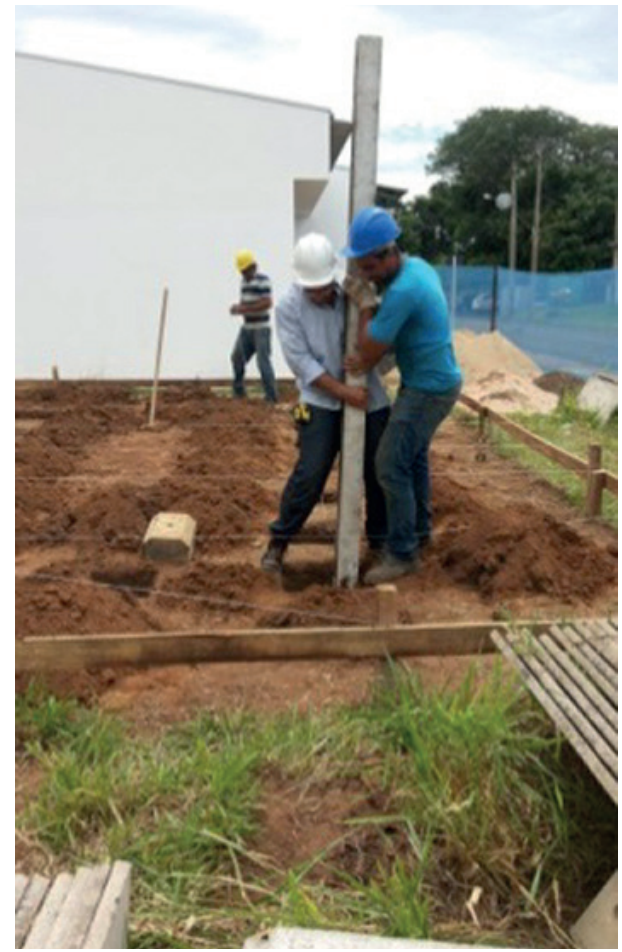

Figura 3 - Colocação do pilar de concreto pré-moldado. 


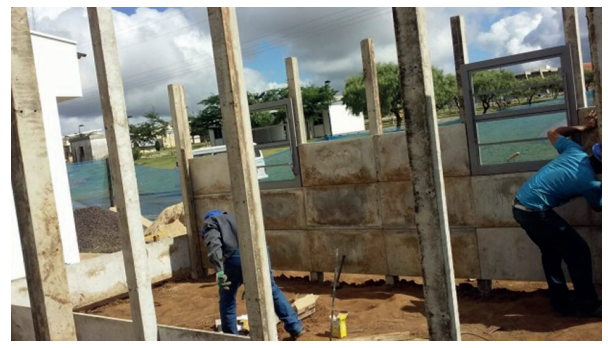

Figura 4 - Vista geral da montagem da IP.

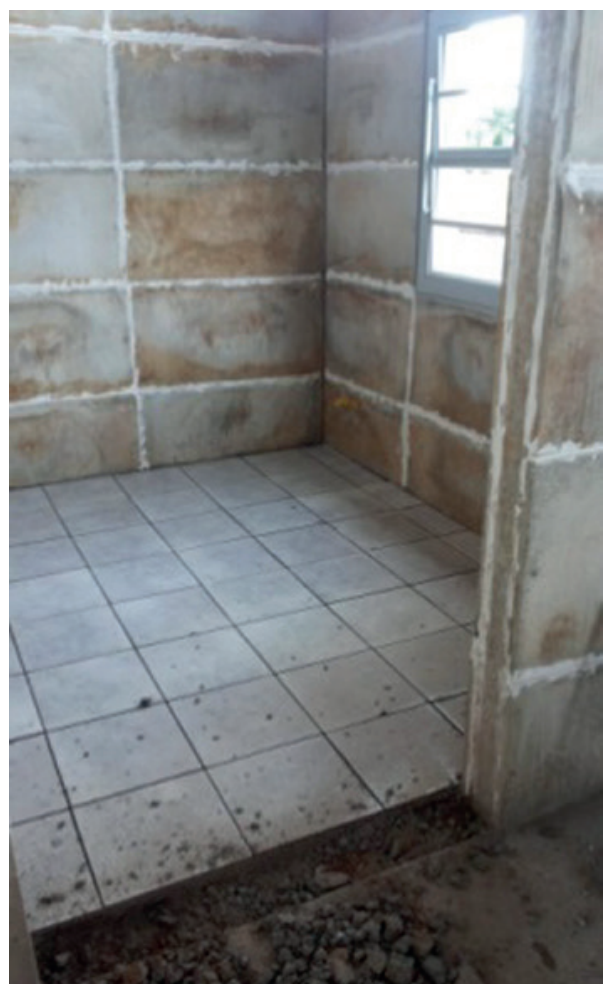

Figura 6 - Assentamento de piso cerâmico e calafetação das placas pré-moldadas de concreto.

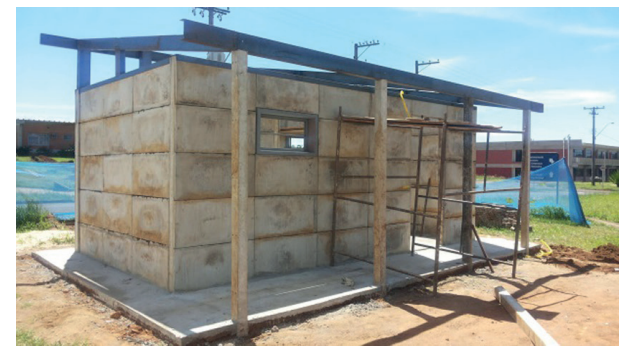

Figura 5 - Vista da montagem da estrutura metálica de coroamento e de fixação da cobertura.

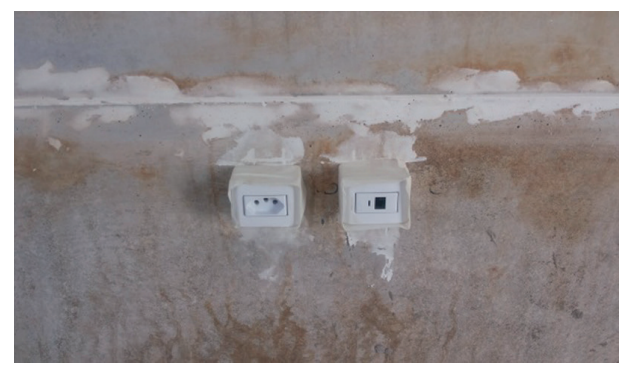

Figura 7 - Detalhe da fixação das instalações elétricas.

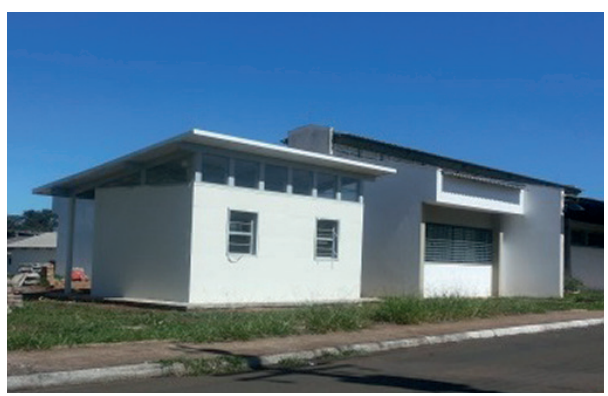

Figura 8 - Vista geral da IP após pintura e instalação dos vidros das esquadrias. 